\title{
Correction to: Grassland fragmentation affects declining tallgrass prairie birds most where large amounts of grassland remain
}

\author{
Mark R. Herse $(D) \cdot$ Kimberly A. With $(D) \cdot$ W. Alice Boyle $(\mathbb{D}$
}

Published online: 12 January 2021

(C) Springer Nature B.V. 2020

Correction to: Landscape Ecol https://doi.org/10. 1007/s10980-020-01064-y

In the original publication of the article, Table 1 was published incorrectly. The level of significance for the modelled fixed effect of grassland edge density on Grasshopper Sparrow occurrence was omitted from the published table. Grassland edge density had a significant negative effect on Grasshopper Sparrow occurrence $(\widehat{\beta}=-0.71$, standard error $=0.09$, $p<0.001)$. The corrected version of Table 1 is shown below.

The original article can be found online at https:// doi.org/10.1007/s10980-020-01064-y.

M. R. Herse - K. A. With · W. A. Boyle

Division of Biology, Kansas State University, Manhattan, KS 66506, USA

M. R. Herse $(\square)$

School of Biological Sciences, University of Canterbury, Private Bag 4800, Christchurch 8140, New Zealand

e-mail: markr.herse@gmail.com 
Table 1 Slope parameter estimates $(\hat{\beta})$ and standard errors (SE) for predictor variables in the most parsimonious (i.e., lowest AICc) models of species apparent occurrence

\begin{tabular}{|c|c|c|c|c|}
\hline Statistic & Grasshopper Sparrow & Henslow's Sparrow & Greater Prairie-Chicken & Upland Sandpiper \\
\hline Sites occupied & $1004 / 2250(45 \%)$ & $99 / 2250(4 \%)$ & $195 / 2250(9 \%)$ & $576 / 2250(26 \%)$ \\
\hline Transects occupied & $74 / 75(99 \%)$ & $36 / 75(48 \%)$ & $30 / 75(40 \%)$ & $58 / 75(77 \%)$ \\
\hline Model fixed effects & Slope estimate (SE) & & & \\
\hline Intercept & $0.03(0.16)$ & $* * *-3.77(0.31)$ & $* * *-6.01(0.63)$ & $* * *-1.90(0.18)$ \\
\hline Grass & $* * * 1.21(0.10)$ & ** $0.89(0.30)$ & $* * * 1.10(0.23)$ & $* * * 0.58(0.13)$ \\
\hline Grass $^{2}$ & $* * *-0.47(0.10)$ & $*-0.84(0.33)$ & & \\
\hline Edge & $* * *-0.71(0.09)$ & $* * *-1.17(0.25)$ & $* * *-0.76(0.18)$ & $* * *-1.36(0.11)$ \\
\hline Grass $\times$ edge & & & & $*-0.21(0.10)$ \\
\hline Number of surveys & $* * * 0.46(0.09)$ & $* * 0.42(0.15)$ & ${ }^{\S} 0.59(0.30)$ & $* * * 0.53(0.10)$ \\
\hline Survey point & $*-0.15(0.07)$ & & $* * *-1.57(0.16)$ & \\
\hline
\end{tabular}

Variance explained

\begin{tabular}{lllll}
\hline Conditional $R^{2}$ & 0.51 & 0.16 & 0.61 & 0.48 \\
Marginal $R^{2}$ & 0.39 & 0.13 & 0.24 & 0.30 \\
\hline
\end{tabular}

Percent grassland ('Grass') and grassland edge density ('Edge') were measured within 400-m radii in models of Grasshopper Sparrows and Henslow's Sparrows, and 1600-m radii for Greater Prairie-Chickens and Upland Sandpipers. Estimates are based on scaled variables and thus directly comparable. Asterisks indicate significance level $\left(* * *<0.001, * *<0.01, *<0.05,{ }^{\S}<0.1\right)$. The proportion of the variance in apparent occurrence explained by each full model versus only fixed effects are indicated by conditional $R^{2}$ and marginal $R^{2}$, respectively, and based on the delta method

Publisher's Note Springer Nature remains neutral with regard to jurisdictional claims in published maps and institutional affiliations. 